DE

M E D I C I N A

T R O P I C A L

$\mathrm{DE}$

S ÃO PAULO

JOURNAL OF THE SÃO PAULO INSTITUTE OF TROPICAL MEDICINE

(1) Universidade de São Paulo, Faculdade de Saúde Pública, São Paulo, São Paulo, Brazil,

(2) Universidade Federal do Acre, Rio

Branco, Acre, Brazil,

(3) Universidade Anhanguera-Uniderp, Campo Grande, Mato Grosso do Sul, Brazil

Correspondence to: Eunice Aparecida Bianchi Galati.

Universidade de São Paulo, Faculdade de Saúde Pública, Departamento de Epidemiologia. Av. Dr. Arnaldo, 715, CEP 01246-904, São Paulo, SP, Brazil. Tel: +55 $1130617112,+551130617786$

E-mail: egalati@usp.br

Received: 30 June 2016

Accepted: 9 February 2017

\section{Epidemiological aspects of American cutaneous leishmaniasis (ACL) in an endemic area of forest extractivist culture in western Brazilian Amazonia}

\author{
Andreia Fernandes Brilhante ${ }^{1}$, Leonardo Augusto Kohatsu Melchior², Vânia \\ Lúcia Brandão Nunes ${ }^{3}$, Cristiane de Oliveira Cardoso², Eunice Aparecida \\ Bianchi Galati ${ }^{1}$
}

\section{ABSTRACT}

The study sought to analyze clinical and epidemiological aspects of cutaneous leishmaniasis (CL) in Xapuri, Acre, Brazil. Data from 2008 to 2014 registered in the notification records of the disease of the Information System of the Complaints of Notification (SINAN), and the data of the Information Department of the Unified Health System (DATASUS) available from 2007 to 2013 were used and analyzed in the light of the statistics of the temporal series by the Prais-Winsten method and chi-squared test. A total of 906 cases were registered with $60.2 \%$ occurring in men and $39.7 \%$ in women. The groups from 0 to 4 years of age $(48.0 \%)$ and from 5 to 19 years of age $(23.3 \%)$ were the most affected. Regarding the clinical forms, $77.7 \%$ presented CL and $22.3 \%$ mucocutaneous leishmaniasis (MCL). Among the 896 cases with information on the diagnostic methods used, Montenegro's skin test predominated (66.4\%), with a positive result of $95.8 \%$ for CL and $99.3 \%$ for MCL. Treatment with N-methylglucamine antimony was performed in $99.4 \%$ of the cases, but discontinuously used in the majority of patients. This study presents information which may be used as a tool for the epidemiological surveillance and control of the disease in Xapuri, a region which depends essentially on forest resources and ecological tourism.

KEYWORDS: Cutaneous leishmaniasis. Rubber extractors. Epidemiology. Amazonia.

\section{INTRODUCTION}

American cutaneous leishmaniasis (ACL) is a metaxenic disease of importance in public health. It is caused by protozoa of the Leishmania genus, transmitted to human-beings by the bite of infected phlebotomine females ${ }^{1,2}$. It is the commonest form of the disease and is manifested mainly by localized ulcerous lesions in the skin and may leave serious scars as sequelae. Furthermore, other clinical manifestations of disease may affect humans, depending on the etiological agent or host immune response, which may still develop forms: disseminated, characterized by lesions pleomorphic, acneiform and papular; Diffuse, also called anergic form, has nodular lesions without forming ulcerations, and the mucocutaneous form resulting in severe deformities of the nasal septum and mouth ${ }^{2}$. It is estimated that 0.7 to 1.2 million new cases occur annually in the world ${ }^{3}$.

According to the Pan American Health Organization (PAHO) report, in the Americas, it was reported 51,098 cases of cutaneous leishmaniasis and mucosal 
form with a incidence rate of 19.76 cases per 100,000 inhabitants, that Brazil holder of $75 \%$ of all cases, followed by Colombia and Peru. Regarding the epidemiology of clinical forms in 2014, approximately $96 \%$ of the cases correspond to cutaneous and $4 \%$ for the mucocutaneous; these latter being more prevalent in Brazil (1,016 reported cases), Peru (343) and Bolivia (228)

In recent years, despite the advances made in the surveillance and control of ACL, the incidence of the disease has continued high in several Brazilian states. In the period from 2001 to 2013, Acre attained the highest incidence of all the Brazilian states (12.8 cases/10,000 inhab.), almost a third greater than the incidence found in the state with the second rank, Mato Grosso (9.0 cases/10,000 inhab. $)^{2}$. The municipality of Xapuri has stood out not only by virtue of the number of cases, but also due to the high incidence of the disease: between 2007 and 2013, the municipality presented an incidence of 81.9 cases/10,000 inhab., amounting to $14 \%$ of all the cases in the state 5 .

Although it is recognized that the incidence of ACL in Xapuri is one of the highest in the state of Acre, little is known about the profile of the human population affected by the disease in the municipality. The objective of this study was to analyze the occurrence of ACL in the municipality of Xapuri in the period from 2008 to 2014 by clinical and epidemiological aspects.

\section{POPULATION AND METHODS}

\section{Study site and study design}

The municipality of Xapuri (Lat.: $10^{\circ} 39^{\prime} 06^{\prime \prime}$ S; Long.: $68^{\circ} 30^{\prime} 16^{\prime \prime} \mathrm{W}$ ), constituted in 1904 , is located in the interior of the state of Acre, in the meso-region of the Vale do Acre, in the micro-region of Brasiléia. To the north it borders the capital Rio Branco, to the west, Sena Madureira, to the southwest, Brasiléia, to the south, Epitaciolândia and to the east, Capixaba and the international frontier with Bolivia (Figure 1). The native vegetation is both open and dense shady forest, the climate is equatorial, humid and hot, the average annual temperatures vary between $23.2^{\circ} \mathrm{C}$ and $25.7^{\circ} \mathrm{C}$, and the average annual rainfall is of $1,373 \mathrm{~mm}^{6}$ (Figure 1).

In the 70 s, the municipality became internationally famous by virtue of the environmental movement led by the rubber extractor and activist, Chico Mendes. Forty percent of the Chico Mendes Extractivist Reserve, a conservation unit created in 1990 and under the control of the federal government, is situated within the municipality. Outstanding in the local economy are products extracted from the natural vegetation, the main ones being rubber and Brazil chestnuts. The municipality covers an area of $5,347 \mathrm{~km}^{2}$ and has a population of 16,091 inhabitants, $36 \%$ of whom reside in

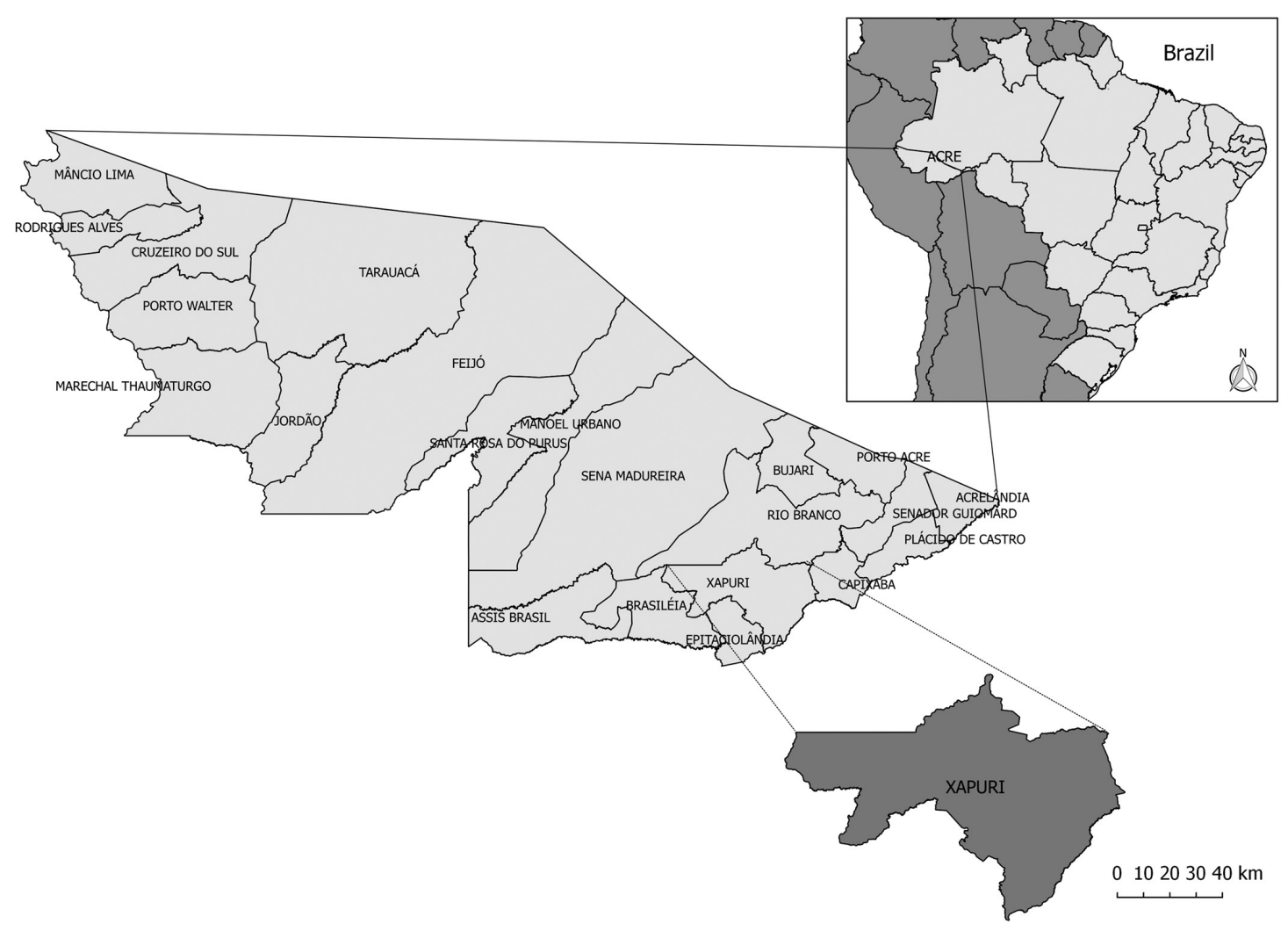

Figure 1 - Political map of Brazil indicating the localization of the State of Acre and highlighting Xapuri municipality. 
the rural zone. The Municipal Human Development Index (IDH) for Xapuri in 2010 was of 0.599 , a level considered low by the Program for Development of the United Nations (PNUD). Xapuri is visited, at the present time, by tourists from various parts of the world, attracted by the incentives to ecotourism ${ }^{6}$.

The population of this study consisted of the autochthonous cases of ACL resident in Xapuri in the period from 2008 a 2014. The data were extracted from the notification forms of the ACL cases of the Ministry of Health obtained through the Epidemiological Information and Surveillance service of Xapuri (Vigilância e Informação Epidemiológica de Xapuri) and the Information System of Notifiable Complaints (Sistema de Informação dos Agravos de Notificação-SINAN). The source of the information on the number of inhabitants by sex, age group and residential condiction was the Brazilian Institute of Geography and Statistics (Instituto Brasileiro de Geografia e Estatística) ${ }^{7}$. Visits were made to the municipality to obtain the data and photographic records and to observe the housing situation.

\section{Data analysis}

The rates of incidence for the study period were estimated for the municipality of Xapuri, the State of Acre, the Amazon Region, the Extra-Amazonian Region and Brazil, for the period from 2007 to 2013, according to the availability of the information from DATASUS ${ }^{5}$. For this, the number of cases was multiplied by ten thousand and then divided by the population in the middle of the period taking the number of years into consideration. This procedure was also used with regard to the variables sex, age and residential condition and the result presented in the form of a bar graph.

The statistical package STATA $13^{8}$ analyzed the statistics of the time series from 2007 to 2013 by the method of analytical self-regression known as Prais-Winsten. This technique corrects the temporal self-correlation of the first order of the residues and classifies the rates of incidence logarithamized as increasing, stationary or diminishing, giving the annual rate of increase as a percentage with a statistical significance level of the order of $95 \%$.

Further, the relative frequencies of the following variables were analyzed by means of the same program: sex, age, schooling, place of residence, type of entry in the registration system, clinical form, method of diagnosis, dose prescribed and treatment. The period investigated for these variables covered the years from 2008 to 2014, in accordance with the data of the Epidemiological Information and Surveillance service of Xapuri (Serviço de Vigilância e Informação Epidemiológica de Xapuri).
The data were submitted to descriptive statistical analysis using Pearson's Chi-squared test for the comparison of the two or more proportions at a confidence level of 95\%. The confidence interval for relative risks was calculated in accordance with Rothman et al. ${ }^{9}$.

\section{RESULTS}

The incidence rates of ACL in Xapuri remained high from 2007 to 2013 (Figure 2). According to DATASUS ${ }^{5}$, the relative risk of the municipality was 4.6 times higher than that of the State and 13.5 times higher than that of the Amazon Region as a whole. When compared to Brazil and the Extra-Amazonian Region this risk rises to 77.5 and 187.6 times, respectively.

The analysis of the historical series of the incidence of ACL (Figure 2) enables one to see that Xapuri presented a slightly diminishing tendency in the period of $-0.7 \%$ (confidence interval of between $-1.1 \%$ and $-0.3 \%$ ), as also did the State of Acre $(-0.6 \%$ with a confidence interval between $-1.0 \%$ and $-0.1 \%$ ). The rates of the other localities presented in Figure 2 remained stable showing that no statistically significant annual variation occurred in the period under analysis.

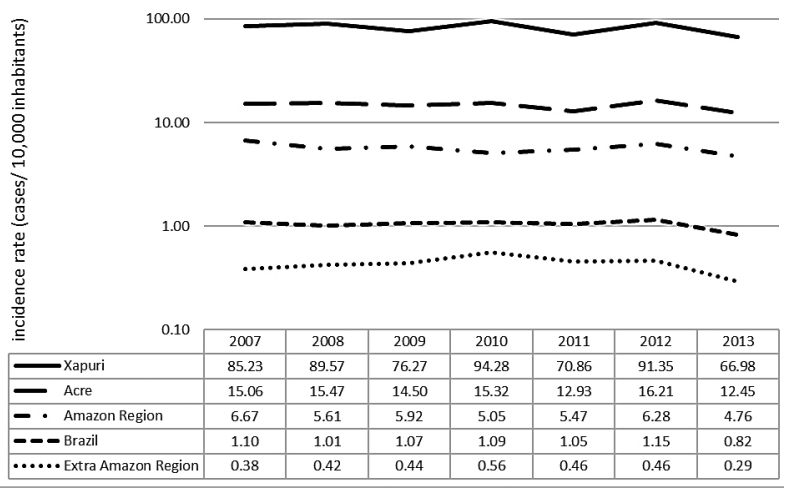

Figure 2 - Rates of ACL incidence on a logarithmic scale in the municipality of Xapuri, Acre State, Amazon Region and Extra-Amazonian Region and in Brazil, from 2007 to 2013. Source: Datasus ${ }^{4}$.

During the period from 2008 to 2014, of the 932 notified cases of ACL in Xapuri, 906 were registered as autochthonous and resident in the municipality. According to the data on residence it was observed that the majority of cases were distributed on the rural properties (98.0\%) known as allotments, these areas belonging to rubber plantations located within the forest. In these localities, the typical situation of the dwellings was either surrounded by or close to the forest (Figure 3).

The distribution of the disease by zone, age and sex shows that young people of both sexes who live in the 


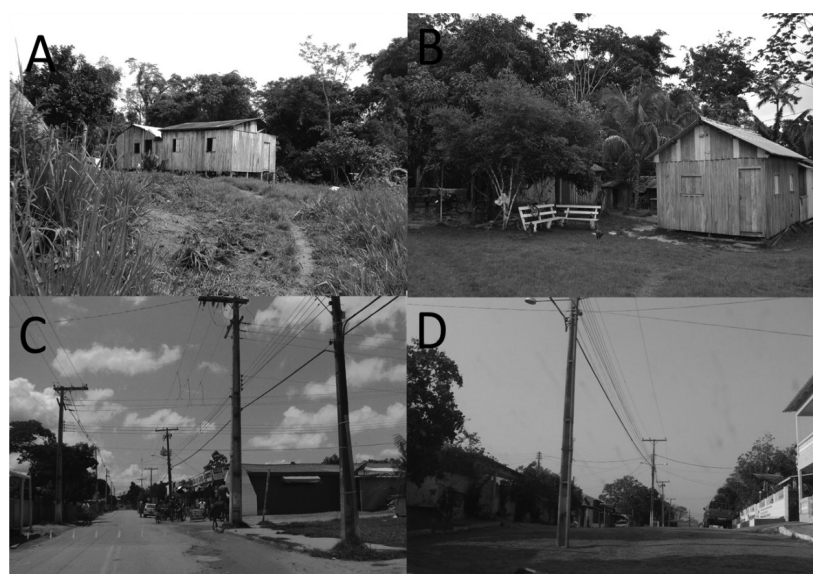

Figure 3 - Photographs of the municipality of Xapuri. A and B) dwellings in the rural zone; $\mathrm{C}$ and $\mathrm{D})$ urban zone. Photo: Teixeira, 2016.

rural zone are more affected than those who live in the urban zone. The range of age groups is also greater in the rural zone. The incidence rates of the disease in the rural zone decrease as age increases for both sexes. The risk of the disease for males is greater, with statistical significance, in all age groups, excepting that of 40-59 years old, however, without statistical significance at a level of $95.0 \%$ (Figure 4; Table 1). The risk of the disease was also statistically significantly (95\%) greater in the child +

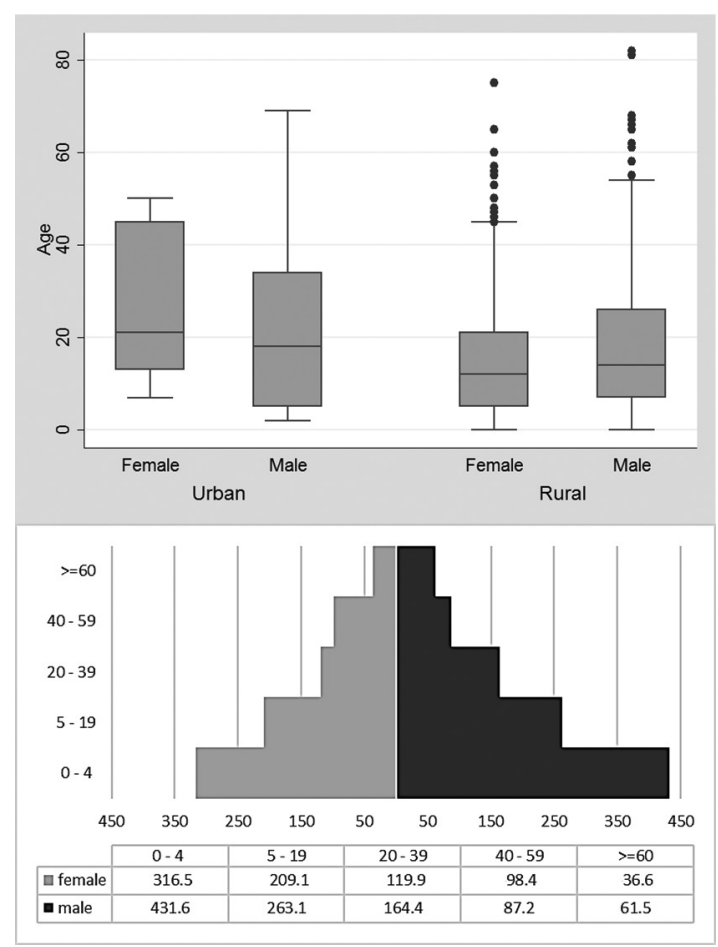

Figure 4 - Upper figure: a boxplot graph of age by sex and home situation of those suffering from ACL in Xapuri, Acre, 2008 to 2014; Lower figure: bar graph of the rates of incidence of ACL by sex and age group of residents in the rural zone of Xapuri, Acre state, 2008 to 2014.
Table 1 - Cutaneous leishmaniasis in the rural population of Xapuri. Relative risk (RR) and confidence interval $(\mathrm{Cl})$ for male:female ratio, by age group.

\begin{tabular}{lcc}
\hline Age group (years ) & $\mathrm{RR}$ & $\mathrm{Cl}$ \\
\hline $0-4$ & 1.36 & $1.18-1.57$ \\
$5-19$ & 1.26 & $1.05-1.51$ \\
$20-39$ & 1.37 & $1.08-1.73$ \\
$40-59$ & 0.89 & $0.67-1.19$ \\
$\geq 60$ & 1.68 & $1.11-2.52$ \\
\hline
\end{tabular}

adolescent population than in that of adults ( $\geq 20$ years old) for females ( $R R=2.36$; CI: $1.90-2.93)$ and males $(R R=$ 2.13. CI: $1.76-2.58)$. The cutaneous clinical form is more prevalent in children and adolescents, while the mucosal forms prevail in adolescents and adults (Figure 5).

As regards schooling, $29.0 \%$ of the individuals affected were below school age and $61.2 \%$ had not completed their basic schooling.

Of the 906 autochthonous cases of ACL 704 (77.7\%) presented the cutaneous form and $202(22.3 \%)$ the mucous form. Among the mucocutaneous cases, 159 contained information about previous lesions or scars of ACL, which $78.8 \%$ had previous lesions or scars and $21.2 \%$ did not have any these skin characteristics. As to the type of entry in the data systems, the new cases predominated absolutely regarding recurrences for both cutaneous $(96.4 \%$ and $3.4 \%)$ and mucous clinical forms (96.5\% and 3.5\%). The use of laboratory criteria to confirm both cutaneous $(85.6 \%)$ and mucous $(81.2 \%)$ cases predominated in relation to the clinical-epidemiological one $(14.4 \%$ and $18.8 \%$, respectively) (Table 2).

Among the cases with information on the diagnostic method used (896), Montenegro's skin test was applied to 595 patients $(66.4 \%)$, the direct parasitological method was performed in 247 (27.6\%) and the histopathological in $54(6.0 \%)$. Montenegro's skin test was positive in more than $95.0 \%$ of both cutaneous and mucous cases. The direct parasitological exam resulted positive in $97.0 \%$ of cutaneous and $66.7 \%$ of mucous forms. In the histopathological test the parasite was found in $73.2 \%$ of cutaneous cases, in $24.4 \%$ the results were negative and $2.4 \%$ showed compatible results. For mucous cases the values of these three categories were very similar (Table 2).

Among the ACL cases with treatment information (873), for $99.4 \%$ of them, the drug of first choice was the N-methylglucamine antimony. However, $8.6 \%$ of the patients (6.9\% with CL and $1.7 \%$ with MCL) were treated with amphotericin B because the first medication failed.

As regards the prescribed dose of the antimony, $80.2 \%$ 


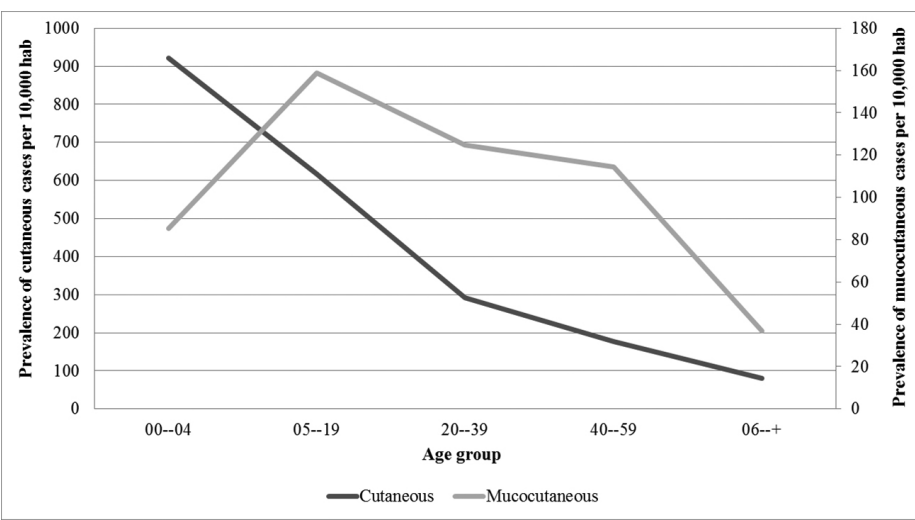

Figure 5 - Prevalence of cases of cutaneous e mucocutaneous leishmaniasis by age group, Xapuri municipality, Acre state, 2008 to 2014 .

Table 2 - Comparison of the cutaneous and mucous clinical forms of ACL according to data of the autochthonous cases notified by SINAN in residents in the municipality of Xapuri, Acre State, 2008 to 2014.

\begin{tabular}{|c|c|c|c|c|c|}
\hline & \multicolumn{2}{|c|}{ Cutaneous } & \multicolumn{2}{|c|}{ Mucous } & \multirow[t]{2}{*}{$\mathbf{p}^{*}$} \\
\hline & $\mathbf{n}$ & $\%$ & $\mathbf{n}$ & $\%$ & \\
\hline \multicolumn{6}{|l|}{ Demographics } \\
\hline Sex & & & & & 0.236 \\
\hline Male & 417 & 59.2 & 129 & 63.9 & \\
\hline Female & 287 & 40.8 & 73 & 36.1 & \\
\hline \multicolumn{6}{|l|}{ Age group } \\
\hline $0-4$ years & 151 & 21.5 & 14 & 6.9 & 0.000 \\
\hline $5-19$ years & 346 & 49.2 & 89 & 44.1 & \\
\hline $20-39$ years & 148 & 21.0 & 63 & 31.2 & \\
\hline $40-59$ years & 48 & 6.8 & 31 & 15.3 & \\
\hline 60 years and above & 11 & 1.5 & 5 & 2.5 & \\
\hline \multicolumn{6}{|l|}{ Zone } \\
\hline Urban & 12 & 1.7 & 3 & 1.5 & 0.835 \\
\hline Rural & 674 & 98.3 & 193 & 98.5 & \\
\hline \multicolumn{6}{|l|}{ Entry in the data system } \\
\hline New case & 676 & 96.4 & 194 & 96.5 & 0.955 \\
\hline Recidivans & 25 & 3.6 & 7 & 3.5 & \\
\hline \multicolumn{6}{|l|}{ Conformation criterion } \\
\hline Laboratory & 603 & 85.6 & 164 & 81.2 & 0.122 \\
\hline Clinical-Epidemiological & 101 & 14.4 & 38 & 18.8 & \\
\hline \multicolumn{6}{|l|}{ Diagnostic Methods } \\
\hline \multicolumn{6}{|l|}{ Montenegro's skin test } \\
\hline Positive & 417 & 95.9 & 159 & 99.4 & 0.031 \\
\hline Negative & 18 & 4.1 & 1 & 0.6 & \\
\hline \multicolumn{6}{|l|}{ Direct Parasitological } \\
\hline Positive & 228 & 97.0 & 8 & 66.7 & 0.000 \\
\hline Negative & 7 & 3.0 & 4 & 33.3 & \\
\hline \multicolumn{6}{|l|}{ Histopathological } \\
\hline Parasite found & 30 & 73.2 & 4 & 30.7 & 0.001 \\
\hline Compatible & 1 & 2.4 & 5 & 38.6 & \\
\hline Negative & 10 & 24.4 & 4 & 30.7 & \\
\hline \multicolumn{6}{|l|}{ Pentavalent Antimony dosing } \\
\hline Adequate & 553 & 80.5 & 120 & 64.5 & 0.000 \\
\hline Below & 111 & 16.1 & 66 & 35.5 & \\
\hline Above & 23 & 3.4 & 0 & - & \\
\hline
\end{tabular}

* Pearson's Chi-squared test 
of the patients with $\mathrm{CL}$ were treated with a dose considered adequate by the Ministry of Health (10 to $20 \mathrm{mg} / \mathrm{kg} / \mathrm{day}$ ), as well as $64.5 \%$ of the patients with MCL $(20 \mathrm{mg} / \mathrm{kg} /$ day $)$. However, $20.2 \%$ of the patients including those with the cutaneous and the mucous forms were treated with doses below the recommended ones, and 3.8\% of the patients with $\mathrm{CL}$ were treated with excessive doses. None of the patients who presented MCL received an excessive dose (Table 2). The duration of treatment varied from 1 to 511 days, though less than $3 \%$ of the cases were precisely followed up as recommended by the Ministry of Health.

As for the progress of the cases, $99.2 \%$ were recorded as cured, $0.4 \%$ gave up the treatment and $0.3 \%$ died from other causes. However, the data reported as cure may contain errors in completing this item in the notification forms, because there are a high number of patients who abandon treatment. There was no notification of death attributed to ACL in the period analyzed.

\section{DISCUSSION}

The Brazilian Amazonian Region has contributed significantly to the maintenance of the high rates of the incidence of ACL in Brazil². The State of Acre has stood out in recent years within this scenario, especially by reason of such municipalities of the micro-region of Brasiléia as Xapuri $^{10,11}$ and Assis Brasil ${ }^{12}$, indicated as one of the main foci of the transmission of the disease.

The study of the epidemiology of ACL in Xapuri has shown that the disease is not distributed homogeneously in the municipality, revealing the existence of various patterns of transmission. The areas of the greatest occurrence are the most isolated ones where the rural workers who survive by the extraction of natural forest products live. In these regions, transmission seems to occur either in intra or peridomiciliary environments given the high incidence, mainly among children and adolescents. In these cases, probably because most of the houses are in the forest areas, where the phlebotomine vectors are attracted to the light and the humans, favoring the intra and peridomiciliary transmission cycle. Parallel to this study, entomological collections were carried out in forested and peri/intradomiciliar environments in ACL foci of the municipality, where the presence of anthropophilic and incriminated species as vectors of Leishmania spp. has been found (Data to be published).

In the age group $\geq 20$ years old the incidence of cases is significantly lower than in that of children together with adolescents. This fact is probably to be explained by the more frequent exposure over the years to the saliva injected by constant sand fly bites which may provide some protective effect in relation to the clinical leishmaniasis ${ }^{13,14}$. A similar pattern of transmission to this has already been found in Brazilian states such as Bahia and Espírito Santo ${ }^{15,16}$. The higher incidence among males can be attributed to occupational activities and also in obtaining sustenance such as fishing and hunting. However, this explanation does not apply to the group of 0 - 4 years of age. Thus other determining factors should be investigated to explain this age pattern.

Rural properties classified as ranches and smallholdings present a smaller number of cases than the socalled allotments belonging to rubber extractors, due to the construction of their dwellings far from the forests and the conversion of the forests into pasture, which hinders the action of the vectors of the disease whose range is limited. It is further possible that the smaller number of cases in these places is also related to the fact that agricultural and cattle-raising activities employ a smaller number of hands per hectare than does forest extractivist activity. Further, study is therefore necessary to determine the pattern of transmission on rural properties which adopt agricultural and cattle-raising activities.

In the urban zone, in view of the low endemicity and the average age observed, it is believed that the transmission is occurring when people move into the forest for reasons such as visits to relatives who live in areas of rubber extraction, for activities related to work or even for activities such as hunting and fishing.

The low schooling level of those who suffer from ACL in the municipality is an expression of their limited socioeconomic and cultural condition. According to local visits was observed the lack of resources and of information may be reflected in the way the population seek to avoid the disease (using the traditional medicine) and in the search for the diagnosis and treatment of the zoonosis.

It is noted in this study that the demographic characteristics of ACL cases in Xapuri are similar to those prevalent in other highly endemic areas in the State of Acre as also in other localities in the northern region of the country, with predominance of the clinical cutaneous form ${ }^{17}$.

As regards diagnosis, Montenegro's skin test is the method most frequently employed in the municipality as well as in several other localities ${ }^{12,16,17,18,19}$. It is considered to be a sensitive test, even giving a positive reaction after the cure of the patient or after treatment. Despite the efficacy of this method and its frequent use at the present time in Brazil for the diagnosis of $\mathrm{ACL}^{2}$, the fact that crossed reactions with other diseases may occur, in the same areas as paracoccidioidomycosis, sporotrichosis, tuberculosis and chromomycosis, among others ${ }^{2,20}$ it would be prudent associate it with more specific methods for a correct diagnosis. Furthermore, it should be taken 
into consideration that Montenegro's skin test does not distinguish past or present infection, raising questions about its effectiveness in endemic areas of disease ${ }^{21}$, because there are reports of patients living in endemic areas who are noninfected and with no clinical manifestations in the past but are positive in the test ${ }^{22}$.

In Assis Brasil (AC), the preference for the use of Montenegro's skin test over the direct parasitological exam was reported, perhaps because of the lack of trained technicians ${ }^{12}$, this same situation may be occurring in Xapuri. Further, in Assis Brasil, the high frequency of the use of the histopathological method attracted the attention of the authors, as it is a costly technique not available through the public health network in this municipality, In Xapuri this technique was few used.

The large number of confirmed cases based on clinicalepidemiological criteria is noteworthy as it underlines the need for the training of technicians for the undertaking of the direct parasitological exam, which permits the definitive diagnosis, as well as being easy to perform and of low cost. Guthmann et al..$^{23}$, in a study undertaken in Peruvian Amazonia, obtained a significant improvement in diagnosis and in the monitoring of the patients after the training of the health personnel. This kind of training can also help in the correct filling-up of the report forms and correct some of the deficiencies found in the epidemiological surveillance system in Xapuri.

Some studies present molecular biology as a diagnostic tool for ACL with high sensitivity, generally giving positive findings in $100 \%$ of the patients analyzed as well as permitting the specific diagnosis of Leishmania $19,24,25,26,27$. However, it is, though, expensive and unavailable under the public health network of the State. It should be emphasized, however, that in Acre there have already been registered human cases of ACL attributed to five species of Leishmania: L. (Viannia) braziliensis, L. (V.) shawi, L. (V.) lainsoni, L. (V.) guyanensis and L. (L.) amazonensis ${ }^{19,24,26}$ which indicate the importance of specific diagnosis, seeing that infections by these species can develop into different clinical forms with diverse prognoses and monitoring needs.

In Xapuri, the majority of the doses of antimoniate prescribed were considered ideal, but there have been cases of sub-dosing, which may indicate either a lack of the medicine or abandonment of the treatment. This latter fact occurs frequently in the State as well as in rural areas of Amazonia, where populations acquiesce in the lack of treatment because of the difficulty of their travelling to the health center ${ }^{11,28}$ particularly in rainy periods seeing that the access roads then become impassable and thus isolate them from the health centers.

It is emphasized in this study that the duration of treatment was discontinuous in almost all of the cases notified, this leading possibly to therapeutic failures, the appearance of cases of relapse, incurable clinical forms and resistance to pharmaceutical products, despite their case-notes' giving the information that the majority of cases led to cure, these may not be trustworthy, because the majority of the patients abandoned their treatment during the period of this study.

Although the cutaneous clinical form is the most prevalent in Acre and also in the municipality of Xapuri, Natal and Silva ${ }^{11}$ had already observed that in some regions of the state the mucocutaneous form was expanding. In fact, our finding 8 years after the period they studied corroborates the observations of these authors, suggesting further studies to clarify the reasons that are leading people to acquire this clinical form.

The occurrence of mucocutaneous form the most of these cases presenting previous lesions or scars of leishmaniasis, reflecst the lack of treatment or its abandonment. This has been happening because the treatment is outpatient and the population affected resides in rural zone and do not have financial resources to stay in the urban area during the treatment period, despite the efforts of local health services in keeping patients in the city. Thus, it is suggested followup studies of the ACL cases in the region with the aim to assess the adherence to the treatment.

Although the highly endemic character of ACL in Xapuri and in the Acre state having been known for many years, there still occur failures in the filling-in of the notification forms. Inconsistent data as to clinical and epidemiological conditions are limiting factors for this kind of study. Beyond that, one cannot overlook the possibility of under notification, because the majority of cases notified in Xapuri are of rural origin and from areas of difficult access, as has also been reported in other localities in $\mathrm{Acre}^{29}$. Despite these limitation, the existing information may provide the health and surveillance organs with data for the control, prevention and management of ACL in the municipality.

Although the disease affects the isolated population of the municipality, the public health authorities should be careful not to neglect the problem. It is necessary to undertake annual campaigns among the population informing them about the leishmaniases in the light of the need for early diagnosis and treatment and adequate followup of the cases, seeing that Xapuri is a region which depends essentially on forest resources and ecological tourism.

\section{ETHICAL CONSIDERATIONS}

This study was approved by the Research Ethics Committee of the Universidade Federal do Acre under Opinion number 062345/2013. 


\section{ACKNOWLEDGEMENTS}

This study was supported by Fundação de Amparo à Pesquisa do Estado do Acre (FAPAC) (grant agreement number PPSUS n $\left.{ }^{\circ} 774445\right)$. The authors also wish to express their thanks to Mrs. Carmelinda Gonçalves, Thayna de Souza and Eliana Costa of the Secretaria de Saúde do Estado do Acre - SESACRE and to Mr. Joaquim Vidal of the Vigilância Sanitária de Xapuri for his logistic support. They would, further, thank Mr. Jorgenilson de Oliveira of the Serviço de Informação de Xapuri for his help with the collection of the information given in this study, and $\mathrm{PhD}$. Paulo Eduardo Ferlini Teixeira for the photographs provided.

\section{CONFLICT OF INTERESTS}

The authors declare no potential conflict of interest.

\section{REFERENCES}

1. Lainson R, Shaw JJ. New World leishmaniasis. In: Cox FEG, Kreir JP, Wakelin D, editors. Topley \& Wilson's microbiology and microbial infections: parasitology. Sydney: Arnold Hodder; 2005. p. 313-49.

2. Brasil. Ministério da Saúde. Manual de vigilância da leishmaniose tegumentar americana. $2^{\mathrm{a}} \mathrm{ed}$. atualizada. $3^{\mathrm{a}}$ reimpressão Brasília: Ministério da Saúde; 2013.

3. WHO. World Health Organization. Leishmaniasis. 2015. [cited 2016 March 21]. Available from: http://www.who.int/ mediacentre/factsheets/fs 375/en/

4. PAHO. Pan-American Health Organization. Leishmaniases: epidemiological reports in the Americas. Washington: PAHO/ Leishmaniases Report n.4; 2016.

5. Ministério da Saúde. Informações de saúde. TabnetDatasus. [cited 2016 Feb 20] Available from: http://www2.datasus.gov.br/ DATASUS/index.php?area $=02$

6. Acre. Governo do Estado do Acre. [cited 2016 March 21]. Available from: http://www.ac.gov.br/wps/portal/acre/Acre/ estado-acre/municipios

7. IBGE. Instituto Brasileiro de Geografia e Estatística. [cited 2016 March 21]. Available from: http://www.cidades.ibge.gov.br/ xtras/uf.php?lang=\&coduf $=12 \&$ search $=$ acre

8. StataCorp. Stata Statistical Software: release 13. Texas: College Station, Stata Press Publ.; 2013. Available from: http://stata. com/manuals13/pdf

9. Rothman KJ, Greenland S, Lash TL. Modern epidemiology. $3^{\text {rd }}$ ed. Philadelphia: Lippincott Williams Wilkins; 2008.

10. Silva NS, Viana AB, Cordeiro JA, Cavasini CE. Leishmaniose tegumentar americana no Estado do Acre, Brasil. Rev Saúde Pública. 1999;33:554-9.
11. Silva NS, Muniz VD. Epidemiologia da leishmaniose tegumentar americana no Estado do Acre, Amazônia brasileira. Cad Saúde Pública. 2009;25:1325-36.

12. Oliart-Guzmán H, Martins AC, Mantovani SAS, Braña AM, Delfino BM, Pereira TM, et al. Características epidemiológicas da leishmaniose tegumentar americana na fronteira amazônica: estudo retrospectivo em Assis Brasil, Acre. Rev Patol Trop. 2013;42:187-200.

13. Davies CR, Gavgani SM. Age, acquired immunity and the risk of visceral leishmaniasis: a prospective study in Iran. Parasitology. 1999;119(Pt 3):247-57.

14. Castellucci LC, Almeida LF, Jamienson SE, Fakiola M, Carvalho ME, Blackwell JM. Host genetic factors in American cutaneous leishmaniasis: a critical appraisal of studies conducted in an endemic area of Brazil. Mem Inst Oswaldo Cruz. 2014;109: 279-88.

15. Sessa PA, Barros GC, Mattos EA, Carias VRD, Alencar JTA, Delmaestro D, et al. Distribuição geográfica da leishmaniose tegumentar americana no estado do Espírito Santo-Brasil. Rev Soc Bras Med Trop. 1985;18:237-41.

16. Ampuero J, Macêdo V, Marsden P. Características clínicas da leishmaniose tegumentar em crianças de 0 a 5 anos em uma área endêmica de Leishmania (Viannia) braziliensis. Rev Soc Bras Med Trop. 2006;39:22-6.

17. Martins ML, Rebêlo JMM, Santos MCFV, Costa JML, Silva AR, Ferreira LA. Ecoepidemiologia da leishmaniose tegumentar no município de Buriticupu, Amazônia do Maranhão, Brasil, 1996 a 1998. Cad Saúde Pública. 2004;20:735-43.

18. Chagas AC, Pessoa FAC, Medeiros JF, Py-Daniel V, Mesquita EC, Balestrassi DA. Leishmaniose tegumentar americana (LTA) em uma vila de exploração de minérios - Pitinga, município de Presidente Figueiredo, Amazonas, Brasil. Rev Bras Epidemiol. 2006;9:186-92.

19. Tojal da Silva AC, Cupolillo E, Volpini AC, Almeida R, Romero GA. Species diversity causing human cutaneous leishmaniasis in Rio Branco, state of Acre, Brazil. Trop Med Int Health. 2006;11:1388-98

20. de Lima-Barros MB, Schubach A, Francesconi-do-Valle AC, Gutierrez-Galhardo MC, Schubach TM, Conceição-Silva F, et al. Positive Montenegro skin test among patients with sporotrichosis in Rio de Janeiro. Acta Trop. 2005;93:41-7.

21. Goto H, Lindoso JAL. Current diagnosis and treatment of cutaneous and mucocutaneous leishmaniasis. Expert Rev Anti Infect Ther. 2010;8:419-33.

22. Sassi A, Louzir H, Ben Salah A, Mokni M, Ben Osman A, Dellagi K. Leishmanin skin test lymphoproliferative responses and cytokine production after symptomatic or asymptomatic Leishmania major infection in Tunisia. Clin Exp Immunol. 1999;116, 127-32.

23. Guthmann JP, Arlt D, Garcia LML, Rosales M, Sanchez JJ, Alvarez E, et al. Control of mucocutaneous leishmaniasis, a 
neglected disease: results of a control programme in Satipo Province, Peru. Trop Med Int Health. 2005;10:856-62.

24. Oliveira JGS, Novais FO, Oliveira CI, Cruz-Júnior AC, Campos $\mathrm{LF}$, Rocha AV, et al. Polymerase chain reacton (PCR) is highly sensitive for diagnosis of mucosal leishmaniasis. Acta Trop. 2005;94:55-9.

25. Venazzi EAS, Roberto ACBS, Barbosa-Tessmann IP, Zanzarini PD, Lonardoni MVC, Silveira TGV. Polymerase chain reaction with lesion scrapping for the diagnosis of human American tegumentary leishmaniasis. Mem Inst Oswaldo Cruz. 2006; 101:427-30.

26. Teles CBG, Medeiros JF, Santos APA, Freitas LAR, Katsuragawa TH, Cantanhede LM, et al. Molecular characterization of American cutaneous leishmaniasis in the tri-border area of Assis Brasil, Acre State, Brazil. Rev Inst Med Trop Sao Paulo. 2015; 57:343-7.
27. Guerra JAO, Prestes SR, Silveira H, Coelho LARC, Gama P, Moura A, et al. Mucosal leishmaniasis caused by Leishmania (Viannia) braziliensis and Leishmania (Viannia) guyanensis in the Brazilian Amazon. PLoS Negl Trop Dis. 2011;5:e980.

28. Lainson R, Shaw JJ, Silveira FT, Souza AAA, Braga RR, Ishikawa EAY. Leishmanioses. In: Veronesi R. Tratado de infectologia. São Paulo: Atheneu; 1997. p.1495-7.

29. Silva-Nunes M, Cavasini CE, Silva NS, Galati EAB. Epidemiologia da leishmaniose tegumentar e descrição das populações de flebotomíneos no município de Acrelândia, Acre, Brasil. Rev Bras Epidemiol. 2008;11:241-51. 